\title{
WE WANT THEM, BUT WE WILL NOT SUPPORT THEM: A COMPARATIVE STUDY OF SETTLEMENT SERVICES PROVIDED TO INTERNATIONAL STUDENTS IN THE USA AND CANADA
}

\author{
by \\ Sahar Dadabhoy, B.A, McMaster University, 2018
}

A Major Research Paper

presented to Ryerson University

in partial fulfillment of the requirements for the degree of

\author{
Master of Arts \\ in the program of \\ Immigration and Settlement Studies
}

Toronto, Ontario, Canada, 2020

(C) Sahar Dadabhoy 2020 


\section{AUTHOR'S DECLARATION FOR ELECTRONIC SUBMISSION OF A MAJOR RESEARCH PAPER (MRP)}

I hereby declare that I am the sole author of this Major Research Paper (Insert second line)

I authorize Ryerson University to lend this MRP to other institutions or individuals for the purpose of scholarly research.

I further authorize Ryerson University to reproduce this MRP by photocopying or by other means, in total or in part, at the request of other institutions or individuals for the purpose of scholarly research.

I understand that my MRP may be made electronically available to the public.

Sahar Dadabhoy 
WE WANT THEM, BUT WE WILL NOT SUPPORT THEM: A COMPARATIVE STUDY OF

SETTLEMENT SERVICES PROVIDED TO INTERNATIONAL STUDENTS IN THE USA AND CANADA

\author{
(C) Sahar Dadabhoy 2020 \\ Master of Arts 2020 \\ Immigration and Settlement Studies \\ Ryerson University
}

\begin{abstract}
In recent years, the number of international student's to the USA has plateaued, with many International Students now choosing to migrate to Canada instead. Arguably, for its worldrenounced education from leading post-secondary institutions, as well as possible pathways to Canadian citizenship. The Canadian government has also been quick to recognize the lucrative contributions of international students to the Canadian economy, even expanding immigration policies to create express pathways to citizenship for international students. Despite this, emerging research shows that international students find it difficult to adopt during their time in North America, and face challenges that can potentially hinder their long-term retention in Canada (Chevrier, 2019). Thus, using a comparative and integrative literature review, this research study assesses the structure of settlement service delivery, and current gaps that hinder the delivery of comprehensive settlement programs for international students in the USA and Canada. The findings of this review show that the American and Canadian governments have not taken an active role in supporting international students, and instead downloaded the responsibility of settlement service delivery to post-secondary institutions. Furthermore, privatization of services in America has been somewhat successful, while in Canada it has been largely unsuccessful. The implications of these research findings is that, if Canada wants to continue to retain its ISs population, it must ensure it is doing its part to support the short, and long-term resettlement and integration of international students into Canadian society.
\end{abstract}

Keywords: international students; settlement support for international students; Canadian settlement services; American and Canadian international students 


\section{Acknowledgements}

My sincere gratitude goes to Dr. Sutama Ghosh for not only inspiring my formulation of this MRP, but also for her insight, care and support throughout the entire process. Also, a special thank you to my second reader, Dr. John Shields.

To my ISS colleague, Huda Shaikh, and someone who I was blessed to have found an amazing friend in. Thank you for being a constant support system throughout this program.

Finally, I would like to recognize the unconditional love and support of my parents, Abu \& Mummy, and my Husband, Daniyal. Thank you for always believing in me. Your presence in my life was a constant reminder of why I was in this program.

$\underline{\text { Table of Contents }}$ 


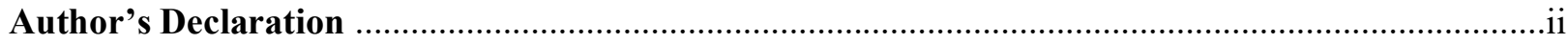

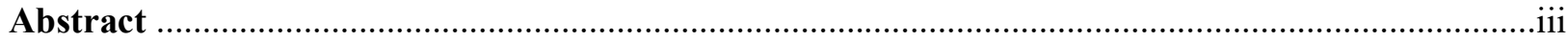

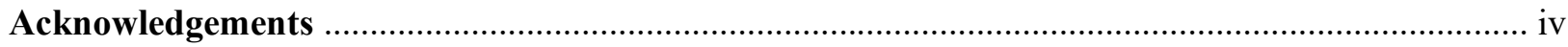

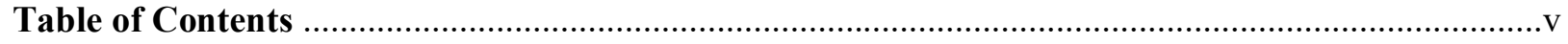

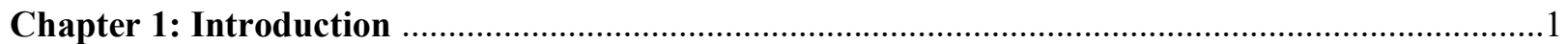

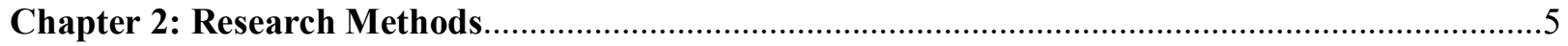

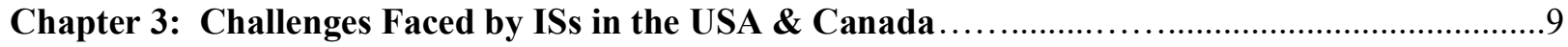

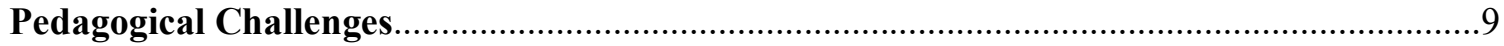

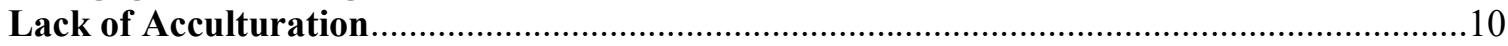

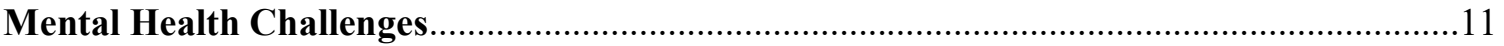

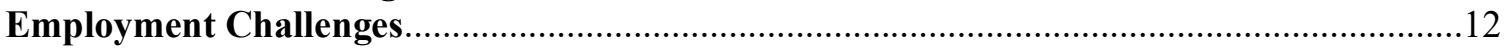

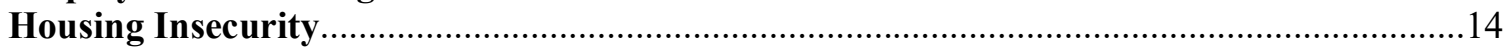

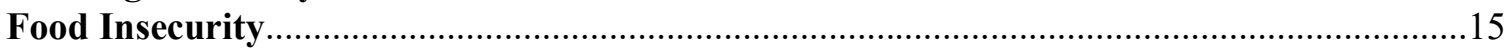

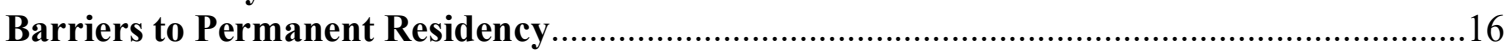

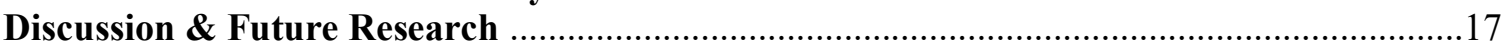

Chapter 4: Assessment of Settlement Services Provided to ISs in the USA \& Canada.....................21

Regionalization of Immigrant Settlement Programs in Canada...........................................25

Internationalization of PSS on American \& Canadian Campuses.....................................26

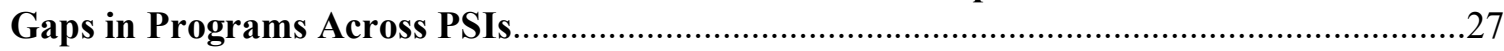

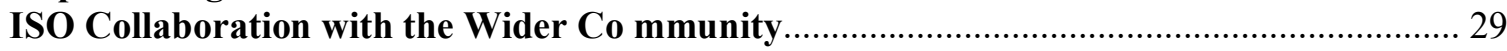

Figure 1.1 Structure of Settlement Program Delivery in the USA ................................32

Figure 1.2 Structure of Settlement Program Delivery in Canada.................................33

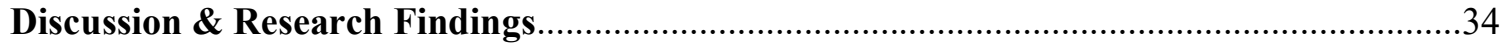

Chapter 5: Conclusions, Limitations of the Study, and Recommendations....................................40

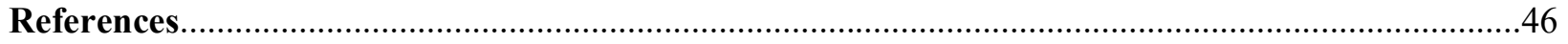




\section{Chapter 1: Introduction}

The mass migration of students from Asia, South America, and Africa to North America has been a growing trend in recent years (Semotiuk, 2018). Large volumes of students from across countries in Asia, South America, and Africa have sought to temporarily migrate to countries such as the USA and Canada in search of a quality education from world-leading post-secondary institutions, and a potential pathway to citizenship. Historically, the USA has been a popular destination amongst students, and the number of ISs in the USA has grown exponentially since the 1950's. (Koh, 2002). For example, the years 1999-2000 were celebrated as "milestone" years for the USA when the number of ISs in the country passed the half a million mark, with a total of 547,867 ISs in America at the time (Koh, 2002). However, in 2018, Forbes released an article titled "International Students Pour into Canada while the U.S and Others Lag Behind (Semotiuk, 2018). Statistics showed that the number of ISs in the USA had plateaued, with a 4\% decline since 2017 (Semotiuk, 2018). On the other hand, the USA's neighbouring country, Canada, simultaneously saw an exponential growth in its ISs population, with the number of ISs rapidly increasing by over 40\% between 2015-2017 (Semotiuk, 2018). It was reported that in 2018, a total of 572,415 ISs were studying in Canada (Gravelle, 2019).

According to the Forbes Magazine (2018) the strict immigration policies implemented by the Trump Administration have made it more difficult for the U.S. to recruit international student interest in recent years. While on the other hand, Canada's reputation for being a leader in world class education, along its reputation for being a champion multiculturalism and diversity has attracted large cohorts of ISs to Canada (Semotiuk, 2018). Students from countries such as India (30\%), China (25\%), France (4\%), Vietnam (4\%), South Korea (4\%), along with a smaller number

of students arriving from countries such as Saudi Arabia, Iran, Nigeria, Brazil have made their way 
to Canada in recent years (CBIE, 2018). For example, a report published by the Canadian Bureau for International Education (CBIE) found that $68 \%$ of prospective ISs had plans to apply for permanent residency, while 65\% plan to work in Canada after graduation (CBIE, 2018). ISs have become a vital component of the Canadian economy, generating an estimated $\$ 21.6$ billion to Canada's GDP in 2018 (Government of Canada, 2019). Ontario, which receives the largest numbers of international students in comparison to other provinces, found that ISs contributed roughly $\$ 3.1$ billion in economic activities within the City of Toronto each year (Government of Canada, 2019). Furthermore, Canada faces significant medium and long-term labour shortages, particularly in the highly qualified professional trades that sustain a modern economy (Government of Canada, 2019). Due to their Canadian education, and lucrative skill set, ISs, upon graduation are perceived are perceived as the "ideal" immigrant (Government of Canada, 2019). Consequently, the Canadian government has attempted to implement express pathways to citizenship to retain its ISs population, which has resulted in the spike of ISs coming to Canada (Roach, 2014).

While large cohorts of ISs make their way to Canada each year, emerging research has shown that ISs find it difficult to adapt to a new country and face numerous challenges (Chevrier, 2019; Sin \& Kim, 2018). Students, journalists, and even scholars have argued that while the federal government considers international students as ideal immigrants, they are failing to adequately support the long-term settlement of students. Consequently, this can potentially hinder the retention rates of ISs in the future. The implications of these research findings is that, if Canada wants to continue to retain its ISs population, it must ensure it is doing its part to support the short, and long-term resettlement and integration of ISs into Canadian society. 
According to Shields et al. (2016), settlement services are "about providing various forms of support and assistance to immigrant populations which help newcomers get established in, and meet their core needs/requirements for their integration into their new homeland, and ultimately to become citizens of that country." Furthermore, Citizenship Immigration Canada states that

"in order for Canada to realize the economic, social and cultural benefits of immigration, newcomers must integrate successfully into Canadian society. The CIC Settlement Program plays a major role by assisting immigrants and refugees to overcome barriers specific to the newcomer experience so that they can undertake their longer-term integration on a similar footing to other Canadians (CIC, 2019)."

According to Omidvar and Richmond (2003), immigrants require settlement services when they first arrive in a new country, along with linguistically and culturally appropriate health and social services as they adapt to their new homes. Thus, settlement programs play a key role in newcomer adaption in their new homes as they provide integral support in easing, and in some cases, overcoming structural barriers. Further, according to Omidvar and Richmond (2003), effective settlement of newcomers is important as it helps to "maintain public support for public support for the continuing high levels of immigration required for our labour force." Hence, amongst scholars and policy makers, the role of settlement programs is to assist immigrants to overcome barriers specific to the newcomer so that they can participate in social, cultural, civic and economic life in Canada. Examples of settlement programs include, but are not limited to, needs assessment programs, language instruction programs, information and orientation, employment programs, and community connections, and legal assistance (CIC, 2019).

Thus, settlement programs play a vital role in not only meeting the short-term needs of newcomers, but also in encouraging the long-term integration of newcomers into Canadian society so they may become vital members of the community (CIC, 2019). Taking from existing scholarship, this paper will also utilize the afro-mentioned definitions when referring to settlement 
programs. For the purpose of this study, welfare programs such as health benefits, child tax benefit, employment insurance, and social assistance will also be analyzed. Since welfare support can play a vital role in the settlement process of an individual, and ease added challenges, it is vital to see whether ISs receive such support from their governments as well (Koning \& Banting, 2013).

The purpose of this literature review is to compare and contrast existing literature on the topic of settlement supports provided to ISs in the USA and Canada. By doing so, this paper seeks to uncover two things. Firstly, this review will provide insight into the current state of knowledge pertaining to settlement supports for ISs in North America. Secondly, through the results of the comparative analysis, this paper seeks to understand how settlement support services for ISs in the USA and Canada compare to one another, and how Canada can strengthen its policies to ensure that its immigrant settlement policies align with its goals to retain its ISs population. This research paper will analyze existing literature to answer the following questions:

\section{How is the structure of settlement service delivery for ISs in the USA and Canada similar and/or different to one another?}

\section{What are the current gaps in settlement service delivery for ISs in Canada?}

The current scope of knowledge pertaining to settlement support services for ISs in the USA and Canada is highly limited. Moreover, despite the USA and Canada being top choices for ISs, there is a complete void in literature pertaining to comparative studies between the two countries on this topic. Thus, the purpose of this research paper is to fill a void in the current scope of literature, while simultaneously conducting a study that seeks to clearly define support systems made available to ISs in both countries. This paper will begin by outlining its research method, followed by a literature review pertaining to the challenges ISs in both countries face, and a critical discussion of this literature. This paper will then assess the state of knowledge on the topic of 
settlement services in the USA and Canada in order to answer the afro-mentioned research questions.

\section{Chapter 2: Research Methods}

The purpose of this literature review is to compare and contrast existing literature on the topic of settlement supports provided to ISs in the USA and Canada. By doing so, the purpose of this research paper is to fill a void in the current scope of literature, while simultaneously conducting a study that seeks to clearly define support systems made available to ISs in both countries. Given the nature of inquiry, a comparative and integrative approach was deemed necessary because of the following reasons, first, as Shields et al. (2016) notes, comparative studies help to "illuminate larger structural, political and other factors" that allow us to understand the context of our policies through a new lens. Secondly, a comparative literature reviews help to cultivate knowledge across boundaries by bringing to light key themes that a national literature might not shed light on (Alba \& Forner, 2014). Thus, this paper draws on literature pertaining to settlement and integration programs and policies for ISs from a cross-national perspective.

Neumann (2006) states that an integrative critical literature review helps scholars "present

and summarize the current state of knowledge on a topic while simultaneously highlighting key themes and avenues for further research." Integrative reviews, thus, have the potential to inform and build on current practices and policies (Knalf, 2005). An integrative review was chosen as the method of research for this paper since this type of review entails a critical analysis of past empirical or theoretical literature, as well as highlights gaps in the literature and avenues for future research, thereby simultaneously creating new knowledge on a given topic (Knalf, 2005).

The literature scan on the research topic was conducted from two different angles with respect to the target group. The literature was examined from (a) the point of view of challenges 
faced by ISs in the US and Canadian contexts. (b) settlement policies and programs available to support ISs in US and Canada. Studies from both peer-reviewed and grey literature relevant to the American and Canadian context were assessed. Methods of information retrieval for academic literature included Ryerson University Library and Archives, Google Scholar, JSTOR, and EBSCOHost. Further, reference list searching was also employed to locate peer-reviewed literature. Key terms used to search for academic literature pertaining to (1) challenges faced by ISs in the USA and Canada, and (2) settlement services available to ISs in the USA and Canada included:

settlement services for immigrants in the USA,' 'welfare programs immigrants in the USA, 'support services for temporary residents, 'ISs settlement programs in Canada,' 'government support for ISs in Canada,' 'post-secondary programs for ISs in Canada/USA, 'immigrant settlement policy in USA/Canada,' 'the role of settlement services in USA/Canada,' 'universities supporting International Students in the USA/Canada,' 'international students in the USA/Canada' 'temporary migrants in Canada,' 'programs for temporary migrants.'

The initial search revealed a total of 200 research articles on pertaining to (1) challenges faced by international students, (2) assistance for international students across Canada and the USA, and (3) settlement services provided by governments for immigrants in general in the USA and Canada. To create a short list, I sorted the research by relevance to the research topic and common themes amongst the articles. Moreover, due to the lack of literature on ISs in the USA and Canada, I chose not to restrict my literature findings to a specific time frame. The earliest research study found dates back to 2007 , hence, the research assessed is fairly recent in scope. In total, this study assessed 60 research articles, both qualitative and quantitative in nature. 
To retrieve grey literature, generic google searches, Ryerson University Library and Archives, and reference list research were utilized. Grey literature was defined as documents or materials outside formal academic channels of publication and distribution, which included community-based research reports, government documents, theses, and information guides. News reports (in print or web-based) were excluded from this review, since the information they provide generally vary by source, and they are not always factually correct. Key words used to search for grey literature included:

'settlement services for immigrants in Canada'

'welfare programs immigrants in the USA'

'support services for temporary residents'

ISs settlement programs in Canada,' 'government support for ISs in Canada'

'ISAs for ISs in Canada/USA'

'settlement services Canada'

'International Students Support Services'

'universities supporting International Students in the USA/Canada'

'support programs for temporary migrants in Canada'

'Immigrant serving agencies and international students'

'immigrant service agencies settlement programs'

The initial search revealed 10 reports comprised of government reports and reports published by immigrant services agencies across Canada on the topics of (1) Canada's internationalization strategy, and (2) settlement services for international students in Canada. Each report was assessed thoroughly for its relevance to the research topic, and common themes between the findings. Amongst the 10 articles reviewed, 5 reports were utilized in this paper.

In the remainder of this major research paper, I will critically assess the key findings of the literature review pertaining to the specific challenges ISs face in the US and Canada. Next, in Chapter 4 I will present a critical review of the literature on the settlement programs that are available to them. In Chapter 5, based on the findings of the literature review, I will make some 
relevant policy recommendations as well as present some of the major imitations of the research study and draw conclusions. 


\section{Chapter 3: Challenges Faced by ISs in USA \& Canada: A Comparative Study}

A search of the extant literature revealed that ISs in the USA and Canada face similar challenges. Within Canadian scholarship, researchers such as Chevrier (2019) and Sin and Kim (2018) have conducted in-depth research on the challenges ISs face. Similarly, scholars such as Mori (2000) and Lin (2012) have extensively studied the settlement challenges of ISs in America. The findings of the research show that ISs in the USA and Canada encounter challenges such as:

\section{(1) Pedagogical Challenges}

(2) Lack of Cultural Acculturation

(3) Mental Health Challenges

(4) Employment Challenges

\section{(5) Housing Insecurity}

(6) Food Insecurity

\section{(7) Barriers to attaining permanent residency}

This chapter will begin with briefly discussing the state of literature pertaining to the afro-mentioned themes, followed by a critical discussion of the literature reviewed.

\section{i. $\quad$ Pedagogical Challenges}

The American literature reviewed found that many ISs arrive in the USA with limited English language proficiency, which impacts their ability to succeed academically. Rivas, Burke, and Hale (2019) and Lin (2012) noted that a lack of English proficiency represented a significant barrier for the students to become academically successful. Mori (2000) also noted that the use of common expressions by American professors posed a challenge for students unaware of cultural nuances. Further, scholars have noted that cultural differences in the 
education systems pose a further challenge for IS in the US as well (Flournoy, 2018; Andrade, 2006; Mori, 2000; Lacina, 2002). For instance, Andrade (2006) found that a student's writing style was closely tied to their culture, which impacted their world view and how they thought about certain concepts.

Similarly, Canadian studies also found that ISS are faced with the additional burden of managing academic workloads in a non-native language, which can make academic success challenging. Hu (2010) and Zang and Zhou (2010) found that Mainland Chinese graduate students had considerable language difficulties, which transpired into them finding basic classroom activities such as in oral presentations, class discussions, and writing assignments challenging. Further, scholars studying ISs in Canada have also noted that cultural differences impact academic success (Braund et al., 2018; Hu, 2010). Countries in the East adopt a Confucian-oriented teaching approach which encourages a lack of critical thinking, while students in North America are encouraged to challenge concepts and engage in critical thinking (Braund et al., 2018; Hu, 2010).

\section{ii. $\quad$ Lack of Cultural Acculturation}

A lack of cultural adjustment is a prevalent theme amongst the American and Canadian literature. For instance, American scholars found that IS face challenges adjusting to a new culture largely because they are constantly trying to find a balance between their own cultures and the culture of their host country. The process of choosing whether to retain one's identity, integrate, or entirely assimilate can cause added stress on a student (Lin, 2012; Lacina, 2000). Further, while many ISs acquire English for academic purposes, they do not necessarily know how to communicate at an informal level (Lacina, 2002; Lee, Kim, Wu. 2019). Hence, not knowing basic slang and cultural nuances can make it challenging for IS to 
take part in conversations with their domestic peers (Lacina, 2002, Mori 2000). According to Inose and Yeh (2003), students who are more likely to speak in English predict lower levels of acculturative distress (Yeh \& Inose, 2003). Their findings are consistent with the findings of Duru and Poyrazli (2011) who found that Turkish ISs in the USA who had higher levels of English language competency reported higher levels of social connectedness and sociocultural adjustment. Further, participants from Lin (2012)'s study also noted experiences of covert discrimination. A student commented, "I have tried to make friends with Americans, but it is not easy. I guess they just do not like to hang out with foreigner (Lin, 2012,pg. 339).”

Similarly, Scott et al (2015) also reported that many ISs in Canada felt that they had "less than desirable interactions with the local students." For instance, Bradley (2000) found that female students from South East Asia felt their universities student culture predominantly focused on alcohol and life in pubs, which was culturally not acceptable to students originating from South East Asia. Brown, Lin, and Durst (2019) also found that ISs in Canada were likely to make friends with students from their own cultures, and even speak to them in their own languages. However, Brown et al (2019) found this creates an ethnic divide and does little to break down the cultural gap between ISs and domestic students.

\section{iii. Mental Health Challenges}

ISs in the USA and Canada are both vulnerable to mental health challenges. A students lack of English fluency, experiences of acculturative stress, discrimination, and lack of social support together can make students vulnerable to depression and anxiety (Ammigan et al, 2019). Zang and Goodson (2011) found that more Asian ISs in the USA reported anxiety symptoms in comparison to non-Asian ISs. Further, Rivas et al (2019) also found that female ISs in the USA were more likely to report higher levels of stress and lower levels of social support in 
comparison to their male counterparts A lack of social support can also cause a student to feel alienated, alone, and in extreme cases, lead to physical illnesses such as insomnia and mental exhaustion (Mori, 2000). Similarly, ISs in Canada also have a hard time adjusting compared to their domestic peers due to the added burden of leaving their homes, being away from family, and having to adjust to a new culture; all in a short amount of time (Andrade, 2006). Unlike the American literature, Canadian literature also reports ISs feeling additional stress due to external factors such as the political situation in their home country (Bradley, 2000).

Scholars studying ISs in America and Canada both found that formal support services were underused by the students. This could likely be because ISs in the USA are wary of support services because counselors are from mainstream Euro-American cultures, and do not understand the complexities of a students culture (Mori, 2000; Lacina, 2002). Lacina (2002) also found that because some students are sponsored by their government to attend schools in the US, students may feel afraid to utilize services provided by their institutions because of fears of deportation. Similarly, in the case of Canada, Li, Monique, and Olivas (2006) and Bradley (2000) found that ISs were also reluctant to use school counselling services due to cultural stigma, or concerns that Western counsellors were inadequate in addressing their needs. McCarthy, Weigold, and Yakunina (2011) found that Chinese ISs rated "no-one" as their preferred source of help for emotional problems on a survey. Bradley's (2000) study reported that students from Europe used counselling services most frequently, while students from Asia and the Middle East sometimes made use of the services, and Students from the Caribbean and East Africa rarely ever utilized support services.

iv. Employment Challenges 
A study by Evive and Gbedu (2009) on African students attending schools in the USA found that financial challenges and barriers towards employment were a key challenge faced by students. The restrictive employment policies laid out by the government for ISs make it increasingly difficult for them to attain employment or earn enough money to support themselves (Evive and Gbedu, 2009). For instance, ISs in the USA must attend school full time to retain status, and can only work part-time campus jobs (McFadden \&Seedorff, 2017). In order to work off-campus, students need to complete one academic year, and off-campus employment must be authorized by the ISs institution (McFadden \&Seedorff, 2017). Additionally, off-campus jobs are usually only for students who want to gain experience in their field while studying. ISs also pay high tuition fees, and the amount of financial aid from the federal government and private and international agencies is low. Further, nearly half of ISs who return to their home countries after graduation reported visa and work-related issues as the primary reasons for returning (McFadden and Seedorff (2017). Discrimination as a result of employer concerns about an ISs ability to communicate or culturally "fit in" were also reported as a deterrent for ISs ability enter the job market (McFadden and Seerdorff, 2017).

In Canada, ISs face similar challenges as well. For instance, Canada's immigration policy is also designed to restrict the hours worked by ISs during their time in school (CIC, 2019). The restrictive policy makes it increasingly difficult for ISs to cover the cost of basic necessities such as housing, food, and even pay tuition (Brown et al., 2019). Furthermore, Brown et al (2019) found international students felt employers preferred to hire local students. According to Kelly et al (2012) because many ISs from non-western countries have never worked before in their home countries, they find it increasingly difficult to find employment 
once they arrive in Canada. Scott et al (2015) found that ISs in Canada found it difficult to attain professional experience through programs such as co-op's or internships due to work permit requirements. Consequently, the lack of professional experience during their academic year's places further places students at a disadvantage upon graduation (Scott et al, 2015). For ISs, finding a job within 90 days of graduation in their field of work is a necessity if they want to continue living in Canada (Chira, 2017).

Scott et al (2015) also found that international students were likely to face discrimination upon entering the work field because employers are hesitant to sponsor workpermits and visas, etc (Scott et al, 2015). One student stated

"we have that extra step, because...jobs are hard to get. Plus, you're not a resident. So, it's like that extra burden that is placed on us. So, we know we are like two times as likely to not get that job, because of that status that we probably have (Scott et al, 2015, pg. 12)."

\section{v. Housing Insecurity}

While American literature does not make mention of housing insecurity faced by ISs, there are some studies within the Canadian literature that have studied housing insecurity amongst ISs in Canada. A study conducted by Calder, Richter, Mao, Burns, Mogale, and Danko (2016) found that some ISs struggled to find affordable housing, whereas some had challenges finding adequate living arrangements. For instance, Burns et al's (2014) study on student homelessness in Canadian Institutions found that student residence fees were extremely expensive, which made it unaffordable for many ISs to live on campus. Moreover, if some international students do choose to live in student residences, most often, they need to leave during breaks, which results in students experiencing temporary housing insecurity (Calder et al, 2016). Students also often lacked support when trying to attain housing or had limited 
knowledge regarding their tenancy rights (Calder et al, 2016). A student from Calder et al's study reaffirmed this, stating

"I had trouble finding an apartment during my internship; there did not seem to be many affordable, 'official' sources available. I used Craigslist, but it felt like a very informal platform that could be unsafe (Calder et al, 2016, pg. 98)."

A lack of housing can also lead to mental health problems for students (Burns et al, 2014). A service provider from Burns et al's (2014) study found that in rare cases, students were at risk for attempting suicide because were dealing with a homeless, financial, or accommodation challenges.

\section{vi. Food Insecurity}

Amongst the American literature reviewed, only one study brought to light the prevalence of food insecurity amongst ISs on US campuses. El Zein et al (2018) found that ISs on US campuses had the highest prevalence of food insecurity when compared to domestic students. According to El Zein et al (2018), food insecurity is often a problem for ISs due to the high tuition fees they are required to pay. Further, because ISs are ineligible to receive government assistance, they have to fend for themselves, which puts them at a heightened risk for being food insecure.

Similarly, amongst the Canadian literature reviewed, only one research study pertaining to food insecurity on Canadian campuses was found (Frank, 2018). Frank (2018) conducted a study on food insecurity among students in a university in rural Nova Scotia. The study found the rate of food insecurity was highest among three groups - Aboriginal, international, and newcomer students (Frank, 2018). Further, the study found that food affordability was correlated to the high cost of tuition, and lack of a student's ability to save for food (Frank, 2018). In the interviews conducted by Calder et. al (2016) the theme of food insecurity also arose. One faculty 
member stated that ISs often underestimate food costs prior to arriving in Canada, hence food insecurity is prevalent amongst ISs (Calder et. al, 2016). Students who are likely to be food insecure are also more likely to have poorer health and academic outcomes (Frank, 2018; Calder et. al, 2016)

\section{vii. Barriers to Permanent Residency}

The challenge of attaining permanent residency was an overarching theme amongst the literature analyzed for ISs in Canada. The number of international students studying in Canada has doubled from 2007 to 2016. For example, in 2018, it was reported that ISs there were a total of 572,415 ISs in Canada in 2018. 60\% of ISs coming to Canada intend to apply for permanent residency upon graduation (Gravelle, 2019). Yet, IS have declined as an immigration source in recent years. Since 2016 , IS only represented $2.8 \%$ of the total permanent residents admitted to Canada, which is a drop of $170 \%$ from 2007 . Chen argues that the drop in ISs transition to permanent residency is largely a result of the way Canadian immigration policy is shaped. While in the past, acquiring permanent residency was a one-step method whereby students were elibgle to apply for express entry shortly after graduation. Students now have 90 days to find employment after graduation and their employer must sponsor them for a work permit. Hence, the current system requires students to acquire significant Canadian experience in their field of study and collect the number of points required to be elibgle to even apply for permanent residency. Thus, as Roach (2011) states, the process of attaining permanent residency has become a "two-step" process. Further, many ISs who are trying to apply for permanent residency find the application process difficult to navigate. Kelly's (2012) research showed that some participants found it challenging to collect the documents required for the application, while some found it challenging to pay for the application itself. 


\section{i. Discussion of Empirical Research Findings}

An overview of the relevant literature has revealed that that ISs in the USA and Canada face similar challenges during their time at their PSIs (post-secondary institutions). Namely, international students in both countries face similar challenges with language acquisition, which can further lead to problems such as pedagogical challenges, lack of acculturation, and mental health challenges. It is possible that ISs in both be countries encounter similar challenges in these categories due to the cultural similarities between America and Canada. For example, the official language of both countries is English, and the language of instruction in both countries is English. Further, the two countries also share a similar campus culture, with the schooling system and campus culture being organized in a similar manner. Additionally, both bodies of literature are dominated by studies on students from Asia and South Asia. Hence, the findings of studies may yield similar results since scholars from both countries have studied the experiences of students from similar, if not the same, demographics. Thus, it is possible that students from countries such as China and India may experience similar challenges during their time in North America in general, irrespective of which country they attend school in.

Further, it should also be noted that French is an official language of Canada. While the current literature does not shed light on Canadian ISs challenges with French, it is possible that some ISs in Canada, for instance, students attending university in Quebec, encounter additional language challenges. Hence, a future study assessing challenges ISs attending a university in a province where the official language is French would provide insight into a critical research area.

The literature review also brought to light that ISs in both countries face similar acculturation stress. For instance, participants from Lin's (2012) study noted they felt domestic students did not like to "hangout" with foreigners. Similarly, Scott et al (2015) noted that 
students on Canadian campuses felt they had "less than ideal interactions with domestic students." Further, students from both countries felt that discrimination existed within the workforce, and employers were hesitant to hire ISs due to cultural bias. In the case of discrimination, it is alarming to see that students and scholars in both countries reported instances of covert racism. In recent years, many IS have chosen to pursue their studies in Canada rather than America due to the countries reputation for diversity and multiculturalism (Semotiuk, 2018). Prior to reviewing the literature, the author assumed that ISs in Canada would report less instances of discrimination in comparison to IS in the USA. Yet, the findings of the literature review depict that discrimination exists on campuses and in the workforce in both countries. Thus, bringing to light key misconceptions about Canadian society. Perhaps, a future study looking more into the experiences of racism on Canadian campuses, and the discrimination ISs face when entering the Canadian workforce would provide a deeper insight into this key topic.

Further, a prevalent theme amongst the Canadian literature was the challenge ISs face in attempting to secure permanent residency. In comparison, the American literature made no mention of ISs and their attempts to secure residency. Instead the literature focuses predominantly on the challenges ISs face during their time in school. This could be because majority of the ISs do not come to America in hopes of attaining residency. The USA does not seem to be concerned with retaining a significant portion of its ISs population (Schmidt, 2007). According to Schmidt (2007), Canada and the United States are drastically different in population size, hence, due its dense population, the USA is not actively trying to retain highly skilled migrants. The USA's restrictive attitude towards ISs is also reflected within its policies for ISs in recent years. For example, when ISs are applying for their student visa, they are 
advised to reinforce that their main purpose in coming to the USA is to solely study and must be able to clearly explain their plan to return home at the end of their program (McFadden \& Seerdoff, 2017).

On the other hand, the Canadian government tries to actively attract ISs in order to retain them for long-term economic benefit (Dawer, 2018). ISs upon graduation, who are young, and have attained a Canadian education are considered a highly skilled, lucrative commodity by the country (Dawer, 2018). The Canadian government also actively works to make pathways to citizenship easier for ISs upon graduation through a series of immigration policies (Dawer, 2018). Hence, unlike ISs in America, when ISs come to Canada, many students come with the intention of migrating to Canada in order to attain a citizenship, which is why, more there are more Canadian studies on the challenges ISs encounter when trying to attain residency.

An analysis of the literature has also that research pertaining to food insecurity amongst ISs is scarce amongst USA and Canadian studies. For example, no research specific to ISs food insecurity has been conducted in American studies. Rather, one study examines ISs experience as a subgroup in a larger study (El Zein et al., 2018). In the Canadian context, it should be noted that Frank's (2018) study was conducted amongst students in rural Nova Scotia. Hence, the findings of a study regarding food insecurity in a large city such as Toronto may differ, thus, pointing to the need for more research on food insecurity amongst ISs settled in urban jungles in comparison to smaller cities.

\section{ii. Addressing the Intersectionality of International Students}

When examining literature pertaining to the challenges international students in the USA and Canada face, there are is one overarching theme that emerges in both bodies of literature. That is, Canadian literature is dominated by studies that attempt to understand challenges faced 
by ISs from the East; namely China. This could be because Chinese students have made up the largest portion of incoming ISs to Canada until recently. Only in recent years has Canada see an increase in ISs from parts of the world such as South Asia and the Middle East. While American literature is also dominated by studies on ISs from Asia, there is also some research pertaining to a more diverse demographic of students such as Turkish and Ghanaian ISs.

Further, the literature review indicated the challenges a student may encounter vary by their cultural background, and that ISs cannot be homogenized as one group. For example, Ge et. al (2019) found that Chinese female participants were likely to face more challenges in their adjustment process due to familial expectations and discrimination from their male counterparts. Bradley (2000) found that South Asian women were likely to face more cultural shock, and more anxiety as a result of their religious beliefs. These findings depict two key elements. Firstly, the experience of ISs may vary depending on their cultural background. Secondly, the research findings pertaining to South Asian women ISs shows that the intersection of one's culture, religion, and gender can impact the settlement process. Hence, there is a need for more culturally diverse, and gender related research pertaining to ISs.

\section{Chapter 4: Settlement Services for ISs in the USA \& Canada: A Comparative Assessment}


The current state of literature pertaining to settlement support for ISs in the USA is largely scarce, with very limited studies having been conducted. On the other hand, there are more studies within Canadian literature that have sought to look at the structure and distribution of settlement supports for ISs. In both the American and Canadian context, the literature can be divided into two themes (1) an assessment of government provided support for ISs and (2) settlement support programs provided by post-secondary higher institutions. The remainder of this section will discuss in-depth the state of American and Canadian literature pertaining to the afro-mentioned themes, followed by a critical discussion on the findings of the literature reviewed.

\section{Section 4.1: Assessment of Government Support provided to ISs in the USA \& Canada}

\section{i. $\quad$ Federally Funded Support Programs for ISs}

The literature reviewed found that ISs are at a considerable disadvantage and have virtually no support from the government during their time in the USA. Schmidt (2007) and Shields et al (2016) argue that the USA's approach towards resettling immigrants is predominantly "laissez-faire." Meaning, immigrants in the USA are held accountable for their own integration and settlement process. Further, the USA does not have an official institution that oversees the programming of immigrant support and settlement policies (Schmidt, 2007; Bloemraad \& De Graau, 2012). Rather, various departments within the federal government fund a limited number of programs and work with states, non-profits, and the community groups to deliver settlement programs (Bloemraad \& De Graau, 2012). However, the programs that are delivered are rather limited and focused. For instance, the government has in place some ESL programs, however, those are predominantly found in elementary, middle, and high schools and meant for young students who have just arrived in the USA (Zimmerman \& Tumlin, 1999). 
There is a lack of ESL programs for adults, which Bloemraad and Graauw (2012) state is to promote the "laissez-fair philosophy towards immigrant integration." In 2002, the Bush administration implemented a new Office of Citizenship whose mission was provide naturalization information and help prepare immigrants for citizenship (De Graauw \& Bloemraad, 2017). This included funding for collaboration with community-based organizations and other partners to welcome immigrants, promote English-language learning, communicate the rights and responsibilities of citizenship, and encourage naturalization (De Graauw \& Bloemraad, 2017). However, these settlement programs are for landed immigrants who are in the process of getting their citizenship, thereby rendering ISs ineligible to access government funded programs (Martirosyan et al, 2019).

The USA, by developed nations' standards, has a weak social welfare system, but the state does provide limited supports to its citizens through a series of programs (Zimmerman \& Tumlin, 1999). Some immigrants may be elibgle to receive social supports such as Medicare, income security, food stamps, student loans (Zimmerman \& Tumlin, 1999). However, welfare support is dependent on citizenship status, and ISs are not considered elibgle (Zimmerman \& Tumlin, 1999). If an IS does try to access public benefits, they are at risk of losing their legal status in the USA since the acceptance of public benefits is interpreted as a declaration that an individual is unable to meet his or her financial obligations (Intercultural Affairs Centre, 2019). The only time a student can qualify for the medical welfare program is if they are in a dire emergency (Intercultural Affairs Centre, 2019). Thus, when ISs arrive in the USA, they have almost no support from the government, and have to either rely on their PSIs, or themselves.

Unlike the USA, since the 1960's, the government of Canada has taken an active role in welcoming and resettling immigrants (Bushell \& Shields, 2018). When landed immigrants and 
refugees with official status arrive in Canada, they are elibgle to access state funded settlement programs (Bushell \& Shields, 2018). The federal, provincial, and municipal governments work together to provide resettlement programs for newcomers. However, Immigration, Refugees, Citizenship Canada, an arm of the federal government takes a leading role in funding majority of the programs, with provincial and municipal governments taking a secondary role (Shields, 2018). While IRCC, provincial, and municipal governments fund settlement programs across the country, ISAs deliver the programs on behalf of the governments (Bushell \& Shields, 2018).

However, just as the USA restricts its limited settlement policies to landed immigrants, so does Canada. Since ISs are considered temporary residents from the time they arrive in Canada till they receive their invitation to apply for permanent residency, they are ineligible to access the settlement services provided by the federal government. For example, Cox (2014) argues that despite ISs facing settlement barriers that are identical to of those of traditional immigrants; they are unable to access government funded services. Chira (2009) states that while immigrant settlement service providers have expressed interest in partnering with post-secondary institutions to deliver international student support, federal funding regulations have prevented such partnerships. Similarly, Roach (2011) found that sometimes, an ISO may attempt to refer ISs to a federally funded settlement provider agency, but in most cases, students are referred back to their post-secondary institutions for support. Hence, according to Gates-Gasse (2010) the onus of successful resettlement and integration is placed almost entirely on the immigrant, with the federal government taking a hands-off approach.

Only in some select provinces are ISs elibgle to receive federally funded settlement support during their transition period from student to permanent residence. For example, nonpermanent residents and foreign nationals who have been selected by employers under the 
Atlantic Immigration Pilot Program (and their spouses and dependants) are deemed eligible to access needs assessment and referrals, and the information and orientation program component (IRCC, 2019). Further, non-permanent residents who have received confirmation of a complete application for Permanent Residence under the Rural and Northern Immigration Pilot (and their spouses and dependants) are also deemed eligible to receive needs assessment and referrals, information and orientation, and community connections program components. If an ISs has studied in the Atlantic Region or been selected under the Rural and Northern Immigration Pilot program, then they are elibgle to access a few select settlement services provided by the federal government (IRCC, 2019).

Just like in the USA, Canada also has a set of welfare programs that it distributes. However, eligibility for these programs is also highly dependent on citizenship. According to Koning and Banting (2013), immigrants with a temporary status, such as ISs, are less protected than newcomers who enter through other migration streams. However, unlike the USA, Canada does offer limited welfare support to its temporary residents. For example, select provinces such as Newfoundland, Nova Scotia, Saskatchewan, Alberta, and British Columbia provide provincial healthcare for ISs (Koning and Banting, 2013). ISs are also elibgle to apply for benefits after living in Canada for 18 months (Koning and Banting, 2013). In respect to social assistance, only Newfoundland, Prince Edward Island, and British Columbia offer social assistance to ISs (Koning \& Banting, 2013). However, despite contributing to the monthly employment insurance program, ISs are ineligible to access this program across the country (Koning \& Banting, 2013).

\section{ii. $\quad$ Regionalization of Immigrant Settlement Programs in Canada}

According to Bushell and Shields (2018) and Flynn and Bauder (2015), the Canadian federal government has sought to dissolve its role in immigrant settlement policy by transferring 
responsibility of funding settlement programs for certain groups to provincial governments, a process known as "regionalization." However, regionalization has created an imbalance in program delivery across the country (Bushell \& Shields, 2018; Flynn \& Bauder, 2015). For example, an international student may be eligible to receive settlement services in a province, but it is possible that not every immigrant settlement agency is funded provincially (Roberts, 2019). For instance, if an individual lives far from a provincially funded ISA, but close to a federally funded ISA, the ISA is not in a position to service them (Roach, 2011). Roach (2011) argues that regionalization has created an imbalance in the types of supports migrants are offered since each

province has sets aside a different budget for settlement programs. Similarly, Lowe (2011) found that while ISs in Ontario may access provincially funded settlement services, of all the settlement services offered in Ontario, only $20 \%$ of settlement services are funded by the province, compared to $80 \%$ which are funded by the federal government (Lowe, 2011). Further, in provinces such as British Colombia, Manitoba, New Brunswick, Nova Scotia, PEI, Saskatchewan, and Quebec, and Saskatchewan, ISs are elibgle to access specific programs within immigrant settlement agencies (Roberts, 2019). However, eligibility is entirely dependent on the province an international student is residing in, and thus, there is no s standardized structure across the country (Roberts, 2019).

Section 4.2: Assessing Post-Secondary Support for ISs in the USA \& Canada

i. Internationalization of Post-Secondary Student Services on American \& Canadian

\section{Campuses}


Bista (2015), Bartram and Terano (2011), and Jaffer (2014) found that ISOs in the USA have moved away from providing traditional counselling programs, and instead adopted a more inclusive approach towards program delivery. Since 1925, schools across the USA have taken part in a greater restructuring of their counselling programs, to include ISs specific services such as certified international student advisors, thereby, taking an active role in providing students with settlement programs (Jaffer, 20014). Bista (2015) found that since the mid 1900's, hiring preferences of international student advisors have changed from hiring an individual who merely has the desire to help and knowledge of intercultural sensitivity, to a person with a background in counseling or formal training in intercultural communication. There is an increased focus on universities hiring culturally aware counsellors who can adopt best practices for supporting ISs (Bista, 2015). As Bista (2015) states, "some have taught English as a foreign language overseas, some have participated in study-abroad programs; some are former Peace Corps volunteers, while others were international students who chose to remain in the United States." According to Bista (2015) and Jaffer (2014) the move towards implementing wholesome support services is because higher educational institutions in America feel they must provide special supports in order to upkeep university internationalization efforts.

Consequently, Jaffer (2014) found that the increasing international student enrollment on campuses means advisors are required to prepare more resources to address the needs and issues of international students in the U.S. Similarly, Clark's study (2002) summarized the roles of the ISOs as "a facilitator for international student activities; an advisor on immigration issues; an advocate for various personal needs; an academic advisor." Jaffer's (2014) environmental scan of settlement programs offered to ISs in the USA found that majority of institutions offered international student orientations, counseling, immigration benefit advisement, and clubs. In 
addition, it was found that majority of the schools offered peer mentors and English language support. Similarly, Martirosyan et. al (2019) conducted a study of websites belonging to the top 20 USA universities with the greatest enrollment of international students in 2016. They found all PSIs in the study offered some form of writing support, culture-community bridging program, professional development support such as tax filing services, and even family support services (Martirosyan et al, 2019).

On the other hand, in Canada, according to Flynn and Bauder (2015), a pivotal component of neoliberalism has been the privatization of public services. Consequently, PSIs and employers have been forced to take on the role of settlement service providers (Flynn \& Bauder, 2015). For example, international student offices have become a focal point for international students to become orientated at the university and to seek academic, employment, and legal support (Bauder \& Flynn, 2015; Roach, 2011). Consequently, ISOs are now responsible for providing services beyond what traditional school councillors are required to do. For instance, just as American universities are also doing, ISOs in Canada have taken an active role in providing students with information on how to obtain work permits, deal with immigration related inquiries, academic issues, and personal issues (Roach, 2011). Cox (2014) found that post-secondary institutions are the primary point of contact for services such as employment services and in some cases, basic language classes too, amongst international students in Canada.

\section{ii. Gaps in Programs across PSIs}

Martirosyan et. al (2019), Jaffer (2014), and Bartram and Terano (2011) research findings depict that across America, the services offered by PSIs differ by institution. For instance, Jaffer (2014) found that the range of ISs services at institutions ranged from two programs, to twelve 
programs, depending on the ranking of the institution. For example, Martirosyan et al (2019) found that even among the top 20 international student receiving universities in the USA, there were variations in the types of programs each school delivered. Similarly, in Canada, Bauder and Flynn (2015) argue that the shift towards privatization has resulted in increasing gaps in service delivery, and an imbalance in the types of programs across institutions. The findings from Cox (2014)'s study, who assessed the settlement programs provided by four major universities across Canada reaffirm Bauder and Flynn's (2015) argument. Cox (2014) found that because there is no country wide benchmarking system in place for international student services, support systems were in disarray at campuses coast-to-coast (Cox, 2014). Cox's (2014) findings also mirror Alboim's (2011) argument that Canada has a patchwork of settlement services for international students across the country, depending on the institution at which they are studying.

Furthermore, Chira (2011) and Roach (2011) argue that international student office's on Canadian campuses are designed to deal with pragmatic issues dealt. Consequently, they are unable to provide specialized services for ISs, whose needs often mirror the needs of immigrant communities. For example, participants from Roach's study (2011) reported that students attending PSIs in Toronto felt their schools lacked quality services aimed at aiding their employment during their time in school, which further impacted their employment outcomes after graduation (Roach, 2011). Calders et al (2016) also found that many PSIs are unable to provide on-going, long-term support for students once they graduate from their PSIs. Similarly, Flynn and Bauder (2015) also report that some universities feel the need to work with provincial governments to provide ISs with information prior to graduation in order to retain ISs in Canada. For example, in Newfoundland's Memorial University, the provincial government has provided 
a grant to the university to deliver a professional skills development program for international students (Flynn \& Bauder, 2015).

According to Roach (2011) and Armose (2018), ISOs are unable to provide ISs with information about the PR process because it is beyond their mandate and they do not have the qualifications to provide services regarding immigration processes. An ISO from Armose's

(2018) study stated, "the boundary is life after the post-grad work permit, so we'll sort of get you to that stage [but not really after that]." Consequently, there is a major gap in support services required for those students who wish to remain in Canada permanently (Roach, 2011).

\section{iii. ISO Collaboration with the wider community}

Spacaro argues that international student services units at many American institutions have received insufficient resources and attention to effectively support the international student population. Similarly, Further, Bartram and Terano (2011) found that the lack of finances and resources has resulted in universities to consider cost efficiency in all areas of their operations. Consequently, international student offices have to coordinate with other groups across campus such as student volunteers to properly support ISs. Further, according to Bartram and Terano (2011), students are encouraged to seek out support services across campus themselves too. They argue that the

"horizontal support mechanisms favoured by American universities are not only costeffective/cost-reductive in operation but can also be instrumental in providing quality and meaningful support systems that nurture a range of positive personal and professional qualities by encouraging student independence and self-authorship."

According to Bartram and Terano (2011), self-independence, and the ability for students to seek out programs across campus allows is a key element of support programmes at U.S. universities. Consequently, this allows institutions to lessen the need for expansive departments, 
and instead, develop a cross-institution program delivery system that allows for low-cost but effective support.

Similarly, in Canada, universities also work with other service providers to help support ISs. However, rather than working within their institutions, they try to coordinate with immigrant serving agencies and community organizations. For instance, in Roach's (2011) study one international student office noted that when advisors felt they could not adequately address the needs of their students they were able to connect ISs with government funded service providers. Similarly, another school from the study noted they invited representatives from CIC to explain the residency process to students (Roach, 2011). The ISO provider from Roach's (2011) study stated,

"Bridging is additional resources-for example, settlement agencies. Right? We don't have to refer [international students to] them, but we do. We connect them. We want them to meet at [our institution]. We organize a venue for them to talk to each other and it's all free of charges."

However, the International Student Offices' admitted that their office was an exception, and not all campuses across Canada are able to provide such services. Further, Roach (2011) voiced concerns that while ISOs may attempt to collaborate with ISAs, these services are nonmandated, and thus, not sustainable for schools. In Armose's (2018) study, immigrant serving agencies stated that their organization lacked the space, staffing, and funding to meet the growing demand for international student support services. Thus, while PSIs try to refer students to immigrant serving agencies, students are often referred back to their PSIs (Armose, 2018). Consequently, students are continually bounced between service providers (Roach, 2011; Armose, 2018).

Armose (2018), Goh (2019), Cox (2014), and Roach (2011) also found that PSIs lack the expertise required to provide services to ISs. For instance, university staff from Armose's (2018) 
study felt that their institutions lacked culturally appropriate support services, particularly in the areas of mental health. Thus, would try to divert students to specialized community programs if such programs were available and willing to accept students (Armose, 2018). Flynn \& Bauder (2015) also report that some universities work with provincial governments to provide ISs with information prior to graduation in order to retain ISs in Canada. For example, in Newfoundland's memorial university, the provincial government has provided a grant to the PSI to deliver a Professional Skills Development Program for International Students (Flynn \& Bauder, 2015). 


\begin{tabular}{|c|c|c|}
\hline $\begin{array}{c}\text { Delivering } \\
\text { Party }\end{array}$ & Programs Delivered & Eligibility \\
\hline $\begin{array}{l}\text { Federally } \\
\text { Funded } \\
\text { Settlement } \\
\text { Programs }\end{array}$ & $\begin{array}{l}\text { No official institution that oversees the } \\
\text { programming of immigrant support and } \\
\text { settlement policies (Schmidt, 2007; } \\
\text { Bloemraad \& De Graau, 2012). Various } \\
\text { departments within the federal government } \\
\text { fund a limited number of programs and work } \\
\text { with states, non-profits, and the community } \\
\text { groups to deliver settlement programs } \\
\text { (Bloemraad \& De Graau, 2012). }\end{array}$ & $\begin{array}{l}\text { Ineligible - federally funded } \\
\text { programs are only eligible } \\
\text { to landed residents in the } \\
\text { USA, ISs are considered } \\
\text { "non-status" residents } \\
\text { (Bloemraad \& De Graau, } \\
\text { 2012). }\end{array}$ \\
\hline $\begin{array}{l}\text { Federally } \\
\text { Funded } \\
\text { Welfare } \\
\text { Programs }\end{array}$ & $\begin{array}{l}\text { Residents of the USA receive social supports } \\
\text { such as Medicare, income security, food } \\
\text { stamps, student loans (Zimmerman \& } \\
\text { Tumlin, 1999). }\end{array}$ & $\begin{array}{l}\text { Ineligible - welfare support } \\
\text { is dependent on citizenship } \\
\text { status, and ISs are not } \\
\text { considered elibgle } \\
\text { (Zimmerman \&Tumlin, } \\
\text { 1999). }\end{array}$ \\
\hline $\begin{array}{l}\text { State Funded } \\
\text { Settlement } \\
\text { Programs }\end{array}$ & NIL & $\mathrm{N} / \mathrm{A}$ \\
\hline $\begin{array}{l}\text { International } \\
\text { Student Offices } \\
\text { at Universities }\end{array}$ & $\begin{array}{l}\text { ISOs in universities have undertaken the } \\
\text { responsibility of providing ISs with } \\
\text { settlement services such as orientation, } \\
\text { academic support, employment training, legal } \\
\text { support, and immigration services }\end{array}$ & $\begin{array}{l}\text { ISs are eligible to access all } \\
\text { services at their respective } \\
\text { ISOs with no restrictions }\end{array}$ \\
\hline
\end{tabular}

Figure 1.1 Structure of Settlement Program Delivery in the USA 


\begin{tabular}{|c|c|c|}
\hline $\begin{array}{c}\text { Delivering } \\
\text { Party }\end{array}$ & Programs Delivered & Eligibility \\
\hline $\begin{array}{l}\text { Federally } \\
\text { Funded } \\
\text { Settlement } \\
\text { Programs }\end{array}$ & $\begin{array}{l}\text { The federal government delivers } \\
\text { a nation-wide settlement policy. } \\
\text { Programs include Needs } \\
\text { Assessment and Referrals, } \\
\text { Information Orientation, } \\
\text { Language Training, } \\
\text { Employment-Related, and } \\
\text { Community Connections (CIC, } \\
\text { 2019) }\end{array}$ & $\begin{array}{l}\text { Ineligible - with the exception of: } \\
\text { - } \text { ISs enrolled in the Atlantic } \\
\text { Immigration Pilot Program (and } \\
\text { their spouses and dependants) can } \\
\text { receive needs assessment and } \\
\text { referrals and information and } \\
\text { orientation program components } \\
\text { (CIC, 2019). } \\
\text { - ISs enrolled in the Rural and } \\
\text { Northern Immigration Pilot } \\
\text { program (and their spouses and } \\
\text { dependents) can receive needs } \\
\text { assessment and referrals, } \\
\text { information and orientation, and } \\
\text { community connections program } \\
\text { components (CIC, 2019). }\end{array}$ \\
\hline $\begin{array}{l}\text { Government } \\
\text { Welfare } \\
\text { Programs }\end{array}$ & $\begin{array}{l}\text { The federal government, along } \\
\text { with provincial governments } \\
\text { delivers a series of welfare } \\
\text { programs such as old age } \\
\text { pension, health care, child tax } \\
\text { benefit, employment insurance, } \\
\text { and social assistance }\end{array}$ & $\begin{array}{l}\text { Eligible - in select provinces, with some } \\
\text { restrictions } \\
\text { - } \quad \text { ISs are elibgle to receive } \\
\text { healthcare in Newfoundland, } \\
\text { Nova Scotia, Saskatchewan, } \\
\text { Alberta, and British Columbia } \\
\text { - } \quad \text { (Koning and Banting, 2013). } \\
\text { - } \quad \text { ISs are also elibgle to apply for } \\
\text { child tax benefits after living in } \\
\text { Canada for } 18 \text { months (Koning } \\
\text { and Banting, 2013). } \\
\text { - } \text { ISs are ineligible to access } \\
\text { employment insurance programs } \\
\text { (Koning \& Banting, 2013). } \\
\text { ISs in British Columbia can access } \\
\text { social assistance (Koning and } \\
\text { Banting, 2013). }\end{array}$ \\
\hline $\begin{array}{l}\text { Provincially } \\
\text { Funded } \\
\text { Settlement } \\
\text { Programs }\end{array}$ & $\begin{array}{l}\text { Mixed model approach where } \\
\text { federal and provincial } \\
\text { governments work together to } \\
\text { deliver programs is currently in } \\
\text { place }\end{array}$ & $\begin{array}{l}\text { Eligible - in select provinces, with some } \\
\text { restrictions: } \\
\text { ISs are eligible to receive select } \\
\text { settlement programs from provincially } \\
\text { funded immigrant settlement agencies in }\end{array}$ \\
\hline
\end{tabular}




\begin{tabular}{|l|l|l|}
\hline & & $\begin{array}{l}\text { British Colombia, Manitoba, New } \\
\text { Brunswick, Nova Scotia, PEI, } \\
\text { Saskatchewan, and Quebec (Roberts, } \\
\text { 2019). }\end{array}$ \\
\hline $\begin{array}{l}\text { International } \\
\text { Student } \\
\text { Offices at }\end{array}$ & $\begin{array}{l}\text { ISOs in universities have } \\
\text { undertaken the responsibility of } \\
\text { providing ISs with settlement } \\
\text { services such as orientation, } \\
\text { academic support, employment } \\
\text { training, legal support, and } \\
\text { immigration services }\end{array}$ & $\begin{array}{l}\text { ISs are eligible to access all services at } \\
\text { their respective ISOs with no restrictions }\end{array}$ \\
& & \\
\hline
\end{tabular}

\section{Figure 1.2: Structure of Settlement Program Delivery in Canada}

\section{$\underline{\text { Discussion }}$}

Literature pertaining to settlement provision for ISs is highly limited. Amongst the American literature reviewed, it was found that no current studies exist pertaining to how governments support ISs. Instead, ISs are only studied as a demographic within broader literature studying the welfare state. Further, there is some, but very little scholarship that has looked at support services for ISs through the lens of PSIs. On the other hand, as the number of ISs within Canada grow, so has the scope of literature on this demographic. There is a growing body of knowledge that has empirically looked at how governments and PSIs support ISs. ISs as a demographic are also briefly studied amongst scholars that have examined the Canadian welfare state and immigrant settlement policy during the neoliberal era.

\section{i. Neoliberalism \& the Welfare State}

In regard to how services are delivered by the governments, the review found that governments in the USA and Canada have not taken any significant action in delivering settlement programs for ISs at a national level. The lack of support ISs in America receive can be 
explained by two reasons. Firstly, compared to Canada, the USA has a drastically different approach towards immigration (Shields et. al, 2016). Immigration policy in the USA is largely affiliated with border security, fighting terrorism, and securitizing the border against undocumented immigrants (Shields et al, 2016). The United States does not put significant resources into opening its borders or boosting its immigration levels. The largest number of immigrants who enter the USA come under the family-reunification category; suggesting that settlement becomes a family matter, not requiring significant state assistance (Bloemraad \& De Graau, 2012). Building off its immigration policy, the USA's approach towards resettling immigrants is consequently, predominantly "laissez-faire. (Schmidt, 2007; Shields et al, 2016). Meaning, immigrants are held accountable for their own integration and settlement (Schmidt, 2007). For example, under the family reunification program, family members are expected to be financially responsible for their family members' support (Bloemraad \& De Graau, 2012). Thus, in the USA, a philosophy of sink or swim tends to dominate (Shields et al, 2016).

Secondly, according to Koning and Banting (2013), the access to, and use of mainstream social programs by immigrants in the USA have become politically contested. In 1966, American social policy underwent reform to deny non-citizens access to welfare programs (Koning and Banting, 2013). In stark contrast, while the Canadian welfare state has also undergone significant cutbacks, temporary residents such as ISs can still access some programs. It should be noted that, as a result of regionalization, the review found that eligibility to access welfare programs was largely dependent upon what province ISs resided in.

In comparison to how the USA delivers its welfare programs to non-citizens, Canada is doing considerably better. The literature has shown that ISs in Canada have a little more support from the government in comparison to students in America. For example, in select provinces, 
international students are able to access welfare programs. Furthermore, the Canadian federal government has also allowed immigrant settlement agencies to support ISs in some regions. For instance, non-permanent residents and foreign nationals who have been selected by employers under the Atlantic Immigration Pilot Program (and their spouses and dependants) are deemed eligible to access needs assessment and referrals, and the information and orientation program component (IRCC, 2019). Further, non-permanent residents who have received confirmation of a complete application for Permanent Residence under the Rural and Northern Immigration Pilot (and their spouses and dependants) are also deemed eligible to receive needs assessment and referrals information and orientation program component of settlement programming (IRCC, 2019). If an ISs has studied in the Atlantic Region or been selected under the Rural and Northern. However, it should be noted that these projects are a pilot program the government is currently experimenting with in order to attract immigrants to certain parts of Canada for purposes of economic benefit (Roberts, 2019). Hence, the government has only made the immigrant settlement policy attractive for those wishing to settle in these regions to boost immigration levels in regions that immigrants traditionally do not settle in.

Canada has taken an active role in administering a nation-wide immigrant policy. For example, the government funds settlement services across the nation to assist in the integration and resettlement of newcomers. Yet, just like in the USA, due to an ISs temporary status, other than in the Atlantic provinces, ISs are unable to access these federally funded settlement programs. Shields et al (2016) Bauder and Flynn (2015), Roberts (2019), and Ashton et al (2018) argue that the inability of temporary migrants to access settlement services is at least in part, a result of neoliberal shifts within Canada's immigrant settlement policy. Since the 1980's, the Global North has undergone a dramatic shift towards adopting a neoliberal framework (Shields 
et al, 2016). Under neoliberalism, there is an increase in the privatization of commodities and the commercialization of public goods such as education and health care (Flynn \& Bauder, 2015). Hence, Canadian immigrant settlement policy has been redesigned during the neoliberal era for two purposes. Firstly, to hold immigrants increasingly accountable for their own settlement and integration, and secondly, to restructure the welfare state model to reduce services for certain populations (Shields et. al, 2016). Thus, unlike the USA, Canada does have a national immigrant settlement strategy in place; however, just like in the USA, most ISs are ineligible to access government funded programs due to their temporary status.

\section{ii. Privatization of Settlement Programs}

In regard to the structure of settlement programs from higher institutions, the review found that American PSIs have taken an active role in the delivery of comprehensive settlement programs for ISs. None of the American literature, however, made mention of ISOs calling upon governments to assist in the settlement support of ISs. This could be because the USA does not have an immigrant settlement policy in place; PSIs know that service provision for students is their responsibility, and therefore, actively work to provide quality support programs for ISs. It is possible that universities in America have also undertaken the responsibility of providing supports to ISs for their own benefit. For instance, Jaffer (2014) found that PSIs in America were struggling to retain ISs beyond their first year in school. Hence, she suggests that PSIs in the USA had to take an active role in creating an environment that is committed to an international student's success, hence there is an opportunity for a greater balance between enrollment and retention (Jaffer, 2014). Similarly, Rendón (2004) and Colondres (2005) stated that PSIs in the USA had to take responsibility in providing settlement programs in order to aid in the recruitment and retention of students. Thus, the tone adopted by the scholars suggests that PSIs 
across the USA have taken on an active role in providing settlement programs to students because they recognize the role schools must play if they want to attract and retain students beyond their first year. Consequently, this could also be why there is some uniformity across the country in regard to who is responsible for the delivery of services.

On the other hand, while PSIs in Canada have attempted to take on an active role in providing support services, PSIs are not adequately addressing the needs of ISs. For example, across the country, the programs delivered to ISs through their universities are in disarray. Furthermore, universities and immigrant serving agencies both feel that service provision for ISs in Canada should be a shared responsibility, and that the Canadian government needs to recognize its role in supporting ISs. For example, Roach (2011) states,

"Considering immigrant selection is a federal responsibility and reforms made by the federal government are targeting international students for immigration, they are downloading their responsibilities for the immigrants they have indirectly selected to ISOs and the non-profit agencies-and present findings indicate neither actor has the capacity to take on additional responsibilities."

Thus, as Gates-Gasse (2012) states, “

there is a need for comprehensive settlement services and supports for international students to facilitate a smooth transition towards their full integration and participation in Canadian society (pg. 272).

Since the internationalization of higher education and the long-term retention of ISs in Canada is a goal of the government, there is a call to action for the government to support ISs. However, the Canadian government does not acknowledge their role in supporting ISs. Thus, amongst universities, immigrant serving agencies, and the government, there is a lack of understanding regarding who the onus of responsibility falls on to support the settlement of ISs, which has resulted in a lack of cohesive programs for international students in Canada. 
Furthermore, unlike American scholars, the primary focus of Canadian scholars is not to solely understand how universities are internationalizing to address the short-term challenges of ISs. Rather, scholars have also looked at how support services for ISs can be improved to promote the long-term integration of international students as immigrations. For example, majority of the Canadian studies only looked at how ISs were supported during their transition period from students to graduates, and the support services they receive during this period. Thus, the difference in the state of scholarship, and differences in attitudes adopted by American and Canadian scholars is also a reflection of how ISs are perceived in the two countries.

\section{iii. $\quad$ Future Research}

The existing state of scholarship has also brought to light that more research is needed on settlement support provision ISs in Canada. For example, Bauder and Flynn (2015) found that regionalization has resulted in unequal delivery of programs across provinces. However, their study is not an empirical investigation into the programs provided to ISs by provincial governments. Rather, it should be seen as a paper that provides a springboard for avenues for future research. Clearly, more research is required on ISs and the provincially funded services they have access to. A cross-national, qualitative study, that attempts to incorporate an environmental scan of provincially funded programs for ISs would provide a greater understanding of where services differ between provinces, and how they can be standardized. Further, a research study that assesses the strengths of the Atlantic pilot program, and its impact on retention rates of ISs would prove beneficial. This would provide policy makers with a deeper understanding of whether the governments expansion of eligibility criteria is beneficial, and best practices for ISs settlement programs in the future. 


\section{Chapter 5: Conclusions, Limitations of the Study, and Recommendations}

The aim of this MRP was to answer the two following questions

(1) How is the structure of settlement service delivery for ISs in the USA and Canada similar and/or different to one another?

(2) What are the current gaps in settlement service delivery for ISs in Canada?

The findings of the literature review have brought to light some critical themes. For instance, the structure of settlement program delivery between the USA and Canada is similar, yet distinct at the same time. Both countries have taken a largely hands-off appd towards assisting international students, however, to an extent, the Canadian federal and provincial governments have support services for selective international student populations. Further, both countries have privatized the delivery of settlement programs by making universities accountable for providing students with services. In America, this downloading of services has been somewhat successful, to the extent that PSIs have taken on this responsibility. However, in Canada, the downloading of responsibility has resulted in (1) a lack of cohesive programs for ISs across the country, (2) a lack of programs aimed at addressing the unique short and long-term needs of ISs, and an (3) overburdening on international student offices and advisors.

These themes have allowed for a greater understanding of the structure of settlement programs for ISs in the American and Canadian context, and areas for improvement. Secondly, the findings have shown that while there is a growing body of knowledge on the topic of settlement programs for ISs, there is a complete void in comparative studies between the USA and Canada. Furthermore, as illustrated throughout this MRP, Canada's main objective is to retain its ISs population. ISs in Canada are a vital commodity for the government and for universities. Therefore, ISs access to comprehensive and structured settlement programs can 
assist in addressing the short-term challenges ISs in Canada face, which can further contribute to their long-term integration. However, as Gates-Gasse state, "both governments and universities feel the other is positioned to gain the most from the presence of international students, leaving the discussion at a standstill (2012, pg. 272)." Thus, the findings of this MRP have shown that if Canada wants to attract and retain ISs from across the world, it must actively work to revaluate its policies to align with its immigration goals.

\section{i. Limitations of the Study}

This study has attempted to contribute to the current body of scholarly work by bringing to light key findings on the topic of settlement support for ISs in the USA and Canada. However, this MRP is not without limitations. Firstly, due to restrictions of time and scope, this paper was unable to conduct primary research, such as interviews with international student advisors. Conducting primary research to understand the challenges and gaps in service delivery from the perspective of ISOs would have proven beneficial to this study, especially due to the lack of American research on this topic. For example, there is a lack of American research studies on the topic of settlement supports for ISs. This research paper only assessed a total of five research studies pertaining to support services provided by universities for ISs in the USA. While the Canadian scholarship identified numerous short comings in programs provided by universities, the American literature only addressed one gap in programs provided by universities. Thus, it is important to acknowledge that the findings of this paper may be limited in scope as a result of a lack of existing research on this topic. Perhaps, a future study researching the challenges faced by international student offices across American institutions would bring to light a deeper understanding of gaps in programs across American PSIs. 
Secondly, this paper has also only looked at the challenges of undergraduate students in universities and settlement programs available to them. However, it should be noted that college students in the USA and Canada are an entirely separate demographic, whose experiences this paper did not address. Recent Canadian data suggests that the number of ISs entering colleges is growing rapidly, with the total number of college attending ISs possibly even being higher than the number of ISs in universities (Gravelle, 2019). Hence, this research topic can also be duplicated with college attending ISs as the demographic of study. It is plausible that a comparative research study assessing the structure of settlement program delivery between colleges and universities would also yield for interesting results and help identify gaps in program delivery amongst various levels of PSIs. Despite these imitations, this study has attempted to contribute to the current body of scholarly work by bringing to light key findings that can inform policy makers, higher-education institutions, and academics.

\section{ii. Recommendations}

\section{A) Rethinking the term "temporary resident" for ISs}

It was argued earlier that ISs face unique challenges that are distinct from domestic students. ISs face barriers that mirror those of traditional immigrants. Programs delivered by ISAs $^{1}$ are vital to the integration of newcomers into Canada because they are culturally sensitive and designed to address the unique challenges of newcomers. However, ISs are unable to access these federally funded settlement agencies and welfare programs due to their "temporary" status. For example, temporary residents are a category in Canada's immigration

\footnotetext{
${ }^{1}$ It has long been noted that ISA's provide support services that are central to the settlement and integration process of newcomers to Canada. ISAs in Canada offer government funded programs such as English language classes, introduction to the labour market, and community connections. Additionally, ISAs even offer counselling and legal help such as permanent residency applications and work permits.
} 
system, and refer to individuals who are legally permitted to live in Canada for short durations, with limitations placed on who they can work for, where they can live, and what services they have available to support them (Roberts, 2019).

According to Roberts (2019), the term "temporary resident" creates unambiguous, consistent categories that distinguish between eligible and ineligible clients (Roberts, 2019) for government funded programs. Similarly, Koning and Banting (2013) argue that in Canada's welfare state, "migrant classification is used as a tool to distinguish between individuals who are included in, or excluded from, social policy.” By labelling ISs as temporary migrants, the federal government has taken a largely hands-off approach towards assisting ISs in Canada (Ashton et al, 2016). Roach (2011) stresses the importance of redefining who an international student is and what kinds of service needs they have as potential immigrants. She further notes that if integration in Canada is truly perceived as a "two-way process," and ISs are a lucrative migrant class, then the government must extend its eligibility criteria to include ISs. Thus, CIC settlement-funding model must be expanded to ensure that international students are elibgle to use immigrant settlement services (Cox, 2014).

\section{B) Reforming Program Deliverv Specific to ISs Across the Country}

The review found that a key component of regionalization and privatization is the unequal delivery of settlement programs across the country. An ISs choice of residence is a key determiner in the services that they have access to. Similarly, depending on a university an ISs attends, the programs that are made available to them may differ, even amongst schools within the same province. However, I do recognize that the neoliberal framework within which our current policies are designed makes it highly unrealistic to call upon the federal government to take complete responsibility of service provision for ISs. Instead, this paper calls makes recommendations for 
the federal government, provincial governments, and PSIs to work together to ensure more cohesive settlement program delivery across the country. Since all three parties benefit from ISs, it is vital that each group does their part to support the retention of ISs.

Currently, while the provincial government funds services for ISs, they only fund select ISAs. As Cox (2014) found, often times provincially funded ISAs are of no use to ISs because they are located too far from campuses. In order to ensure that ISs can access provincially funded ISAs, provincial governments should make a conscious effort to fund ISAs that are located centrally, and accessible from PSIs. The federal government and provincial government should also work together to administer a set of standardized codes that universities across the country who host a large ISs population must adhere to. Currently, there is no benchmarking system in place for PSIs that host ISs. In order to provide a cohesive program system, there needs to be a policy in place that calls upon schools across Canada to have key programs in place.

Furthermore, the federal government must take a more active role in increasing funding and eligibility criteria for immigrant settlement agencies so they can provide services for ISs. Perhaps, a service-delivery model that allows for greater collaboration between ISAs and PSIs would be beneficial. For example, the federal government should create and fund a settlement program specific to ISs that can be delivered by universities and immigrant settlement agencies together. In this model, universities would be responsible for providing programs pertaining to employment services for newcomers, language programs specific to newcomers, professional development support, and preliminary information regarding the permanent residency process. Immigrant settlement agencies, on the other hand, could assist universities by providing ISs with extended services after graduation pertaining to the permanent residency process and spousal support pre-graduation and after graduation. Further, because immigrant settlement agencies 
usually have ethnically diverse counsellors who are aware of newcomer needs, the government should provide resources to allow for ISAs to provide counselling services for ISs as well. A mixed delivery and funding model, where the government provides funds to deliver programs, and universities and immigrant settlement agencies work together to deliver interconnected, yet distinct programs would entail a balance approached towards settlement program delivery. 


\section{Bibliography:}

Andrade, M. S. (2006). International students in English-speaking universities: Adjustment factors. Journal of Research in International education, 5(2), 131-154

Ammigand, R., Drexlerd, M. L., Williamson, A. A., \& Guerra, N. G. (2019). Prevalence and correlates of depressive symptoms among international students: implications for university support offices. Journal of International Students 2019 Vol 9 Issue 1, 9(1), 129-148.

Akanwa, E. E. (2015). International students in western developed countries: History, challenges, and prospects. Journal of International Students, 5(3), 271-284.

Arthur, N., \& Flynn, S. (2011). Career development influences of international students who pursue permanent immigration to Canada. International Journal for Educational and Vocational Guidance, 11(3), 221-237.

Arthur, N., \& Popadiuk, N. (2010). A cultural formulation approach to career counseling with international students. Journal of Career Development, 37(1), 423-440.

Arthur, N. (2017). Supporting international students through strengthening their social resources. Studies in Higher Education, 42(5), 887-894.

Armos, N. (2018, August 30). Support Services for International Students in British Columbia. AMSSA. Retrieved from https://www.amssa.org/wp-content/uploads/2018/09/SupportServices-forInternational-Students-in-BC-Aug-2018.pdf

Ashton, W., Pettigrew, R. N., \& Galatsanou, E. (2016). Assessment of settlement services systems in western and northern Canada: perceptions of settlement provider organizations. Canadian Ethnic Studies, 48(3), 69-89.

Bradley, G. (2000). Responding effectively to the mental health needs of international students. Higher Education, 39(4), 417-433.

Bista, K. (2015). Roles of international student advisors: Literature and practice in American higher education. International Education, 44(2), 87-101.

Bartram, Brendan, and Mayumi Terano. "Supporting international students in higher education: a comparative examination of approaches in the UK and USA." Learning and Teaching 4.2 (2011): 30-44.

Bloemraad, I., \& De Graauw, E. (2012). Immigrant integration and policy in the United States: A loosely stitched patchwork. International perspectives: Integration and inclusion, 205-232.

Bushell, R,, \& Shields, J. (2018). Immigrant Settlement Agencies in Canada: A Critical Review of the Literature through the Lens of Resilience. A Paper of the Building Migrant Resilience in Cities, ASSHRC Partnership Grant Project, York University 
Calder, M. J., Richter, S., Mao, Y., Kovacs Burns, K., Mogale, R. S., \& Danko, M. (2016). International Students Attending Canadian Universities: Their Experiences with Housing, Finances, and Other Issues. Canadian Journal of higher education, 46(2), 92-110.

Cheng, L., DeLuca, C., Braund, H., \& Yan, W. (2018). Grading Policies in Canada and China: A Comparative Study. Comparative and International Education, 47(1), 0_1-24.

Chen, L. H. (2007). Choosing Canadian graduate schools from afar: East Asian students' perspectives. Higher Education, 54(5), 759-780

Chira, S., \& Belkhodja, C. (2013). Best Practices for the Integration of International Students in Atlantic Canada: Findings and Recommendations A Study of the Policies and Practices Surrounding the Settlement of International Students in the Atlantic Provinces..

Campbell, T. A., Adamuti-Trache, M., \& Bista, K. (2018). Employment and earnings of international science and engineering graduates of US universities: A comparative perspective. Journal of International Students, 8(1), 409-430

Cox, C. (2014). International Students in Canada: Policies and Practices for Social Inclusion. Master's thesis, Ryerson University.

Dauwer, A. (2018). Assessing Canada's support of international students: A comprehensive review of Canada's retention and settlement of its "model immigrants" (Vol. 2). RCIS Working Paper No.

De Graauw, E., \& Bloemraad, I. (2017). Working together: Building successful policy and program partnerships for immigrant integration. Journal on Migration and Human Security, 5(1), $105-$ 123.

Denis Gravelle (2019) Keynote: International Students - Stay, Work, Succeed. International Student Pathways and Supports. York University.

Duru, E., \& Poyrazli, S. (2011). Perceived discrimination, social connectedness, and other predictors of adjustment difficulties among Turkish international students. International Journal of Psychology, 46(6), 446-454.

El Zein, A., Mathews, A., House, L., \& Shelnutt, K. (2018). Why are hungry college students not seeking help? Predictors of and barriers to using an on-campus food pantry. Nutrients, 10(9), 1163.

Esses, V., Sutter, A., Ortiz, A., Luo, N., Cui, J., \& Deacon, L. (2018). Retaining International Students in Canada Post-Graduation: Understanding the Motivations and Drivers of the Decision to Stay. CBIE Research in Brief, 8 . 
Evivie, L. G. (2009). Challenges faced by african international students at a metropolitan research university: A phenomenological case study (Order No. 3388961). Available from ProQuest Dissertations \& Theses A\&I; ProQuest Dissertations \& Theses Global. (305094323). Retrieved from http://ezproxy.lib.ryerson.ca/login?url=https://search-proquestcom.ezproxy.lib.ryerson.ca/docview/305094323? accountid $=13631$

Frank, L. (2018). "Hungry for an Education”: Prevalence and Outcomes of Food Insecurity Among Students at a Primarily Undergraduate University in Rural Nova Scotia. Canadian Journal of Higher Education/Revue canadienne d'enseignement supérieur, 48(2), 109-129.

Flynn, E., \& Bauder, H. (2015). The private sector, institutions of higher education, and immigrant settlement in Canada. Journal of International Migration and Integration, 16(3), 539-556.

Forbes-Mewett, H., \& Pape, M. (2019). Social Capital and the US College Experiences of International Student-Athletes and Non-Athletes. Journal of International Students, 9(3), 777-794.

Flournoy, K. (2018). An Investigation of the Challenges Faced By Ghanaian International Students in the American Higher Education System: A Phenomenological Multi-Case Study(Doctoral dissertation, Roosevelt University).

García, H.,A., Garza, T., \& Yeaton-Hromada, K. (2019). Do we belong? A conceptual model for international students' sense of belonging in community colleges. Journal of International Students, 9(2), 460-487. doi:http://dx.doi.org.ezproxy.lib.ryerson.ca/10.32674/jis.v9i2.669

Gates-Gasse, E. (2012). International Students as Immigrants. In H. Bauder (Ed.), Immigration and Settlement: Challenges, Experiences, and Opportunities (pp. 271-295). Toronto: Canadian Scholars' Press In

Global Affairs Canada. (2019, October 11). Canada's International Education Strategy (2019-2024). Retrieved from https://www.international.gc.ca/education/strategy-2019-2024strategie.aspx?lang=eng.

Goh, K. (2019). International Students Who Seek Permanent Residence: SERVICE PROVIDERS' PERSPECTIVE OF AVAILABLE SUPPORTS IN GUELPH-WELLINGTON GuelphWellington Local Immigration Partnership . Retrieved from http://www.guelphwellingtonlip.ca/wp-content/uploads/2019/06/LIP-International-StudentsReport-2019_Final_AODA.pdf

Gopalan, N., Beutell, N. J., \& Middlemiss, W. (2019). International students' academic satisfaction and turnover intentions. Quality Assurance in Education.

Güvendir, M. A. (2018). The relation of an international student center's orientation training sessions with international students' achievement and integration to university. Journal of International Students, 8(2), 843-860.

Ge, L., Brown, D., \& Durst, D. (2019). Chinese International Students' Experiences in a Canadian University. Journal of International Students, 9(2), 582-612. 
Harriss, K. (2019, August 13). Canada must adapt quickly to attract skilled workers, immigration minister says | CBC News. Retrieved from https://www.cbc.ca/news/politics/economiclabour-migration-hussen-oecd-1.5244416.

Hayes, M. (2015). International students' perceptions of campus employment and connections to cultural adjustment. Edgewood College

$\mathrm{Hu}$, J. (2010). Faculty perceptions of Chinese graduate students' communication challenges in the science and engineering disciplines. Comparative and International Education/Éducation Comparée et Internationale, 39(3), 59-80.

Jingnan, H. (2018, July 10). U.S. Degree? Check. U.S. Work Visa? Still A Challenge. Retrieved from https://www.npr.org/sections/ed/2018/07/10/599219792/u-s-degree-check-u-s-workvisa-still-a-challenge.

Jaffer, N. (2014). Campus Personnel's Perceptions of International Student Support Services at Special Focus Institutions of Higher Education.

Kelly, N. T. (2012). International Students as Immigrants: Transition Challenges and Strengths of Current and Former Students. Ryerson University, Toronto, Ontario.

Khanal, J., \& Gaulee, U. (2019). Challenges of International Students from Pre-Departure to PostStudy. Journal of International Students, 9(2), 560-581.

Koh, H. K. (2015). Trends in international student flows to the United States. International Higher Education, (28).

Koning, E. A., \& Banting, K. G. (2013). Inequality below the surface: Reviewing immigrants' access to and utilization of five Canadian welfare programs. Canadian Public Policy, 39(4), 581-601.

Lacina, J. G. (2002). Preparing international students for a successful social experience in higher education. New Directions for higher education, 117, 21-28.

Lau, J., Garza, T., \& Garcia, H. (2019). International students in community colleges: On-campus services used and its affect on sense of belonging. Community College Journal of Research and Practice, 43(2), 109-121.

Li, X., \& Tierney, P. (2013). Internationalization in Canadian higher education: Experiences of international students in a master's Program/Internationalisation dans l'enseignement supérieur canadien: Expériences d'étudiants internationaux dans un programme de maîtrise. Comparative and International Education, 42(2), 1. 
Lin, M. (2012). Students of different minds: Bridging the gaps of international students studying in the US. Online Submission.

Lee, J., Kim, N., \& Wu, Y. (2019). College readiness and engagement gaps between domestic and international students: re-envisioning educational diversity and equity for global campus. Higher Education, 77(3), 505-523.

Lowe, S. (2011). Welcome to Canada?: Immigration Incentives may not be Enough for International Students to Stay, Canadian Diversity, 8(5): 20-24

Moreno, K. A. V., Shields, J., \& Drolet, J. (2018). Settling Immigrants in Neoliberal Times: NGOs and Immigrant Well-being in Comparative Context. Alternate Routes, 29.

McFadden, A., \& Seedorff, L. (2017). International student employment: Navigating immigration regulations, career services, and employer considerations. New Directions for Student Services, 158(2017), 37-4

Martirosyan, N. M., Bustamante, R. M., \& Saxon, D. P. (2019). Academic and Social Support Services for International Students: Current Practices. Journal of International Students, 9(1), 172-191.

Mori, S. C. (2000). Addressing the mental health concerns of international students. Journal of counseling \& development, 78(2), 137-144.

Nakache, D., \& Dixon-Perera, L. (2015). Temporary or transitional? Migrant workers' experiences with permanent residence in Canada. Institute for Research on Public Policy, (55).

Neumann, L. W. (2006). Social Research Methods: Qualitative and Quantitative Approaches. Boston: Pearson Educatio

Popadiuk, N., \& Arthur, N. (2004). Counseling international students in Canadian schools. International Journal for the Advancement of Counselling, 26(2), 125-145.

Pero, R., \& Smith, H. (2014). In the "service" of migrants: the temporary resident biometrics project and the economization of migrant labor in Canada. Annals of the Association of American Geographers, 104(2), 401-411.

Roach, E. (2011). Service needs and gaps for international students transitioning to permanent residency in a" two-step" immigration process: a Toronto-based study. Master's thesis, Ryerson University.

Roberts, S. E. (2019). The Bureaucratic and Political Work of Immigration Classifications: an Analysis of the Temporary Foreign Workers Program and Access to Settlement Services in Canada. Journal of International Migration and Integration, 1-20. 
Rivas, J., Hale, K., \& Burke, M. G. (2019). Seeking a Sense of Belonging: Social and Cultural Integration of International Students with American College Students. Journal of International Students, 9(2).

Rao, P. (2017). Learning challenges and preferred pedagogies of international students: A perspective from the USA. International Journal of Educational Management, 31(7), 10001016.

Sangganjanavanich, V. F., Lenz, A. S., \& Cavazos Jr, J. (2011). International students' employment search in the United States: A phenomenological study. Journal of Employment Counseling, 48(1), 17-26.

Scott, C., Safdar, S., Desai Trilokekar, R., \& El Masri, A. (2015). International Students as 'Ideal Immigrants' in Canada: A disconnect between policy makers' assumptions and the lived experiences of international students. Comparative and International Education/Éducation comparée et internationale, 43(3), 5.

Semotiuk, A. J. (2018, November 16). International Students Pour Into Canada While The U.S. And Others Lag Behind. Retrieved from https://www.forbes.com/sites/andyjsemotiuk/2018/11/16/international-students-pour-intocanada-ahead-of-projections/.

Sparaco, K. K. (2012). The Development of an International Student Advisor: A Grounded Theory Study (Doctoral dissertation, Drexel University).

Shields, J., Drolet, J., \& Valenzuela, K. (2016). Immigrant settlement and integration services and the role of nonprofit providers: A cross-national perspective on trends, issues and evidence. Ryerson Centre for Immigration and Settlement.

Sin, S. C. J., \& Kim, K. S. (2018). How Are We the Same or Different: Information Needs and Barriers of Domestic and International Students. The Journal of Academic Librarianship, 44(6), 712-723.

Whittemore, R., \& Knafl, K. (2005). The integrative review: updated methodology. Journal of advanced nursing, 52(5), 546-553.

Yakunina, E. S., Weigold, I. K., \& McCarthy, A. S. (2010). Group counseling with international students: Practical, ethical, and cultural considerations. Journal of College Student Psychotherapy, 25(1), 67-78.

Yeh, C. J., \& Inose, M. (2003). International students' reported English fluency, social support satisfaction, and social connectedness as predictors of acculturative stress. Counselling Psychology Quarterly, 16(1), 15-28. 
Zhang, J., \& Goodson, P. (2011). Predictors of international students' psychosocial adjustment to life in the United States: A systematic review. International journal of intercultural relations, 35(2), 139-162.

Zhang, Z., \& Zhou, G. (2010). Understanding Chinese international students at a Canadian university: Perspectives, expectations, and experiences. Comparative and International Education/Éducation Comparée et Internationale, 39(3), 43-58.

Zimmermann, W., \& Tumlin, K. C. (1999). Patchwork Policies: State Assistance for Immigrants Under Welfare Reform. Occasional Paper Number 24. Assessing the New Federalism: An Urban Institute Program To Assess Changing Social Policies. 